\title{
Experiencia de conservación ex-situ de Solanum fernandezianum (Solanaceae)
}

\section{Experience of Conservation ex-situ of Solanum fernandezianum (Solanaceae)}

\author{
Jaime Solano ${ }^{1}$, Leonardo Anabalón ${ }^{1} \&$ Enrique Hauenstein ${ }^{2}$ \\ ${ }^{1}$ Laboratorio de Biotecnología y Mejoramiento Vegetal, Escuela de Agronomía y \\ ${ }^{2}$ Escuela de Ciencias Ambientales, Facultad de Recursos Naturales, Universidad Católica de Temuco, Chile. Rudecindo \\ Ortega 02950, Temuco, Chile. \\ jsolano@uct.cl
}

\begin{abstract}
Solanum fernandezianum is an endemic species in danger of extinction the Robinson Crusoe Island, Chile. The fruit was collected during March and April of 2002. The seeds were storaged for a year to $4^{\circ} \mathrm{C}$. The percentage of germination in laboratory conditions was $14.3 \%$. After 22 weeks plants initiated flowering and fruiting. The conservation strategy considered germination of seeds, production of plants in incubation chamber, transplantation to pots and pots arranged in a greenhouse.
\end{abstract}

Los recursos fitogenéticos constituyen la base biológica de la seguridad alimentaria mundial. Estos recursos, a su vez, están formados por la rica diversidad de material genético que contienen las variedades tradicionales y los cultivares modernos, así como las plantas silvestres afines a las cultivadas por el hombre. Además, constituyen un depósito de adaptabilidad genética que sirve de garantía ante el peligro potencial presentado por los cambios medioambientales y económicos (FAO 1996).

Uno de los cultivos alimenticios mundiales más demandados es la papa (Solanum tuberosum L.), por su alto contenido de almidón, con una fuente diversa de germoplasma utilizada para su fitomejoramiento. En este contexto se puede cruzar con la mayoría de sus parientes silvestres, incorporando resistencia a estrés (Hijmans \& Spooner 2001). Entre estas papas silvestres se encuentra Solanum fernandezianum Phil., serie Etuberosum, se caracteriza morfológicamente por ser una planta herbácea rizomatosa, con tallos y hojas glabras, y flores de color azul violeta (Contreras \& Spooner 1999). Es originaria de la Isla Robinson Crusoe en el Archipiélago de Juan Fernández, Parque Nacional y Reserva de la Biósfera de Chile, es una especie endémica con una distribución restringida sólo a esta isla en áreas semidespejadas con abundante presencia de helechos arborescentes y herbáceos, la vegetación asociada coincide con la reportada por Marticorena et al. (1998). Esta especie ha sido clasificada en peligro por Stuessy et al. (1998), Danton et al. (1999), Ricci (2006); y vulnerable por Ricci (1989, 1990, 1992).

La flora vascular del Archipiélago posee un alto grado de endemismo, de 211 especies nativas, 132 (63\%) son endémicas (Marticorena et al. 1998, Ricci 2006), siendo uno de los números de especies endémicas por unidad de área más altos del mundo (Roger et al. 1983, Stuessy et al. 1992).

El material silvestre de esta especie presenta un alto valor con respecto de la resistencia a plagas y enfermedades: al nemátodo dorado (Globodera rostochiensis (Wollenweber) Behrens) (Hanneman \& Bamberg 1986), resistencia al virus del enrollamiento de la hoja de la papa (PLRV), al virus del mosaico rugoso (PVY) y al virus del mosaico suave (PVA) (Valkonen et al. 1992). En híbridos en los que participa $S$. fernandezianum se encontró resistencia a heladas, hipersensibilidad al virus $\mathrm{Y}$, tolerancia al virus del enrollamiento de la hoja y resistencia a marchitez bacteriana, siendo una especie muy susceptible al tizón tardío causado por el hongo Phytophthora infestans (Montagne) de Bary (Hijmans et al. 2003). Por otra parte, estudios sobre potencial de flujo génico entre especies de papas cultivadas y silvestres mostraron que al usar en los cruzamientos accesiones de $S$. fernandezianum, ellas fueron fértiles para la totalidad de las semillas producidas (Jackson \& Hanneman 1996).

La mayor amenaza actual de esta especie en su hábitat es su consumo por animales exóticos, tales como la cabra (Capra hircus L., 1758) y el conejo europeo (Oryctolagus cuniculus L., 1758), considerados plagas para la isla, lo cual aumenta el riesgo de extinción (Ricci 2006).

Considerando que aún existe escasa información relacionada con la conservación $e x$-situ de esta especie en Chile, salvo los estudios de Ricci (1998, 2006), se realizaron ensayos de germinación, establecimiento y aclimatación que permitan la conservación de esta papa silvestre. 
Entre los meses de marzo y abril de 2002 se realizó una expedición de recolección al Archipiélago de Juan Fernández. El principal sitio de recolección correspondió al camino a Plazoleta Yunque en Isla Robinson Crusoe, situado a 257 m de altitud (3339 `9,03“'S; 7850`45,9“'W).

Para la obtención del germoplasma se recolectaron bayas maduras, las que se limpiaron y guardaron en bolsas de papel con su correspondiente codificación y almacenadas transitoriamente en neveras de icopor. Posteriormente fueron secadas en laboratorio a temperatura ambiente por 30 días. Finalizado el período de secado, se extrajeron las semillas de los frutos y luego se almacenaron a $4{ }^{\circ} \mathrm{C}$ por el período de un año en tubos de polipropileno estériles. Para el análisis de germinación, las semillas se incubaron en una cámara de germinación a $22{ }^{\circ} \mathrm{C}$. El análisis se basó en las normas ISTA (2006), para esto se dispuso de una muestra de 400 semillas, que fueron sembradas con 4 repeticiones de 100 semillas cada una en placas petri con sustrato TP (Fig.1).

Las plántulas obtenidas fueron trasplantadas a contenedores de poliestireno expandido y luego a maceteros de 1 y 10 L de capacidad, todas provistas de turba estéril y bajo condiciones controladas de aclimatación hasta la obtención de plantas adultas. Se consideró un fotoperiodo de 16 horas y una temperatura constante de $22 \pm 2{ }^{\circ} \mathrm{C}$ en cámara de incubación, seguido de un periodo en invernadero para un mejor establecimiento. Durante esta etapa, las plantas recibieron abundante riego con aplicaciones semanales de fertilizantes foliares (Fig. 2).
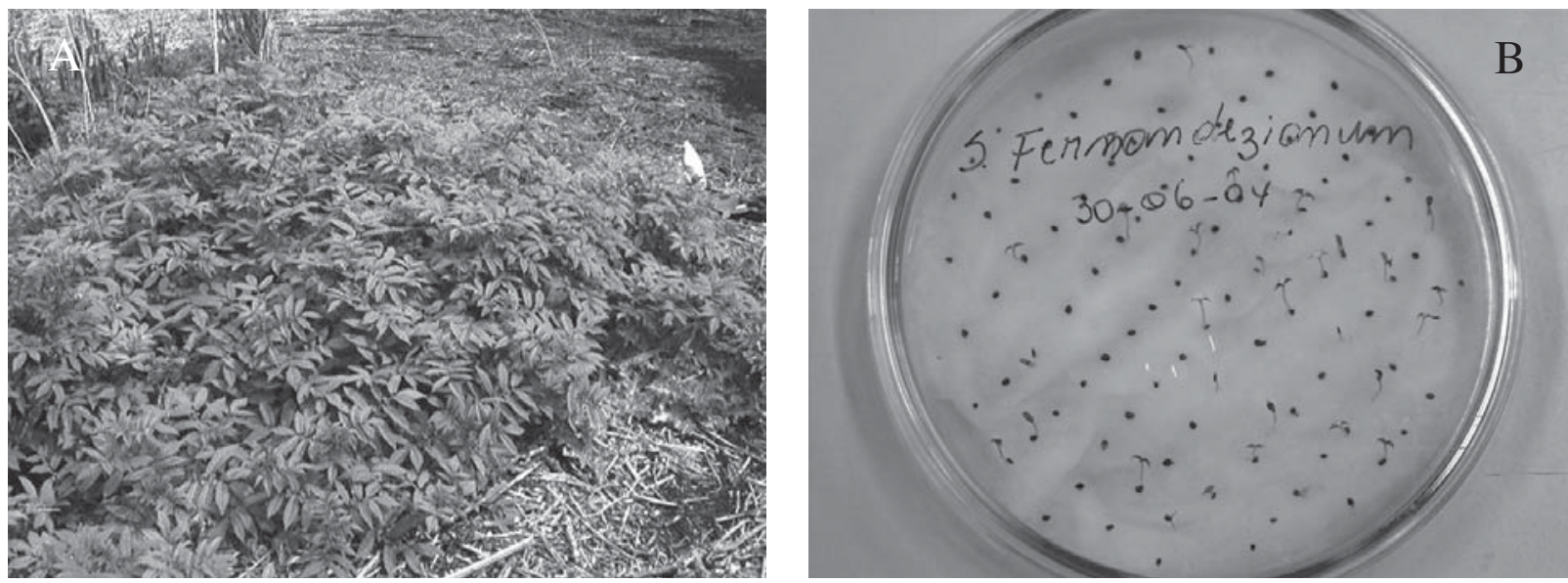

Figura 1. A) plantas de Solanum fernandezianum, B) germinación de semillas (Fotos J. Solano).

Figure 1. A) plants of Solanum fernandezianum, B) germination of seeds (Photographs J. Solano).
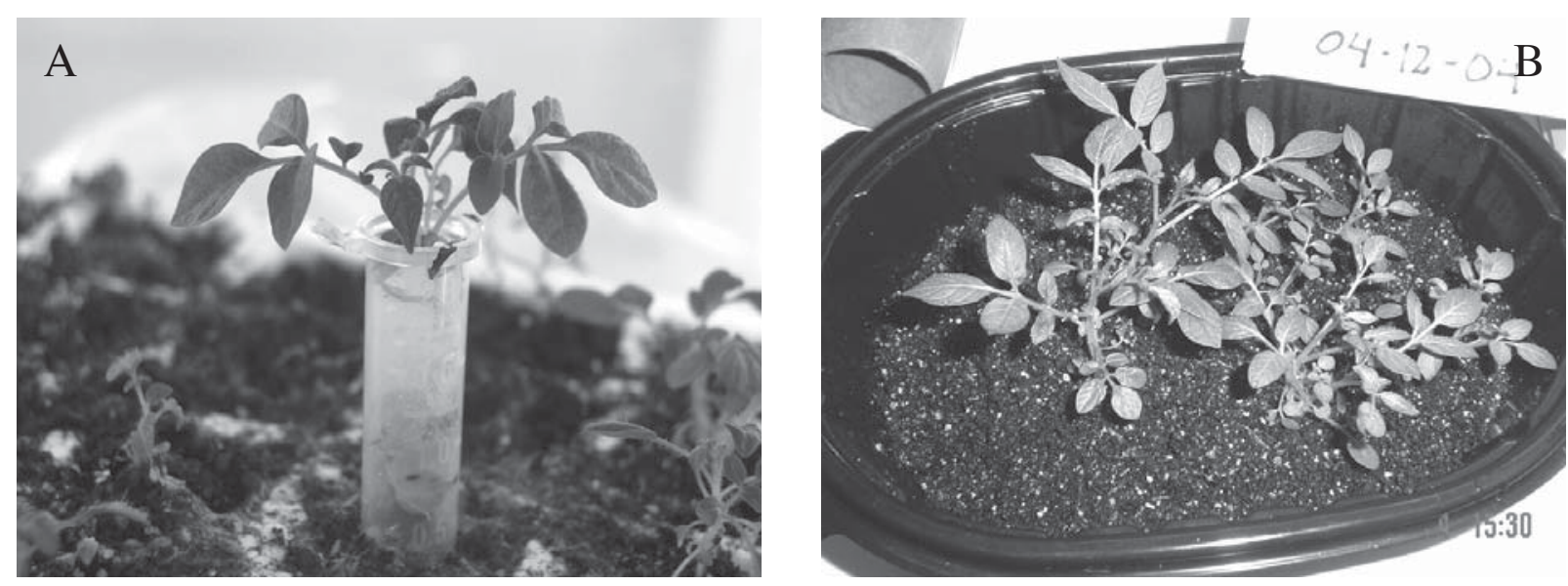

Figura 2. A) Cámara de incubación: producción de plántulas en contenedores de poliestireno expandido, B) cámara de incubación: producción de plantas en macetas (Fotos J. Solano).

FiguRE 2. A) Incubation camera: production of plant in speedling, B) incubation camera: production of plants in pot (Photographs J. Solano). 
Del total de bayas maduras recolectadas se extrajeron 12.674 semillas, de ellas 7.000 fueron incorporadas al Banco de Germoplasma del CRI-Carillanca para su conservación a largo plazo, y 5.674 para los trabajos de laboratorio e invernadero.

Solanum fernandezianum presentó un porcentaje promedio de germinación de un 14,3\%, y aunque este porcentaje fue bajo, los valores son muy similares a los observados por Towill (1983), quien reporta que en semillas de $S$. fernandezianum, almacenadas bajo condiciones herméticas durante 14 años a temperaturas de 1 a $3{ }^{\circ} \mathrm{C}$ con 4 a 5\% de humedad, los porcentajes de germinación alcanzaron un $14,0 \%$. Por el contrario, Ricci (1998) obtuvo un $90 \%$ de germinación, utilizando para ello semillas no almacenadas y estratificadas por 7 días a $-5{ }^{\circ} \mathrm{C}$. Esto indicaría que el almacenaje y la no estratificación de las semillas disminuyen fuertemente su capacidad germinativa, ya que fueron extraídas directamente de los frutos y luego se almacenaron a $4{ }^{\circ} \mathrm{C}$ por el período de un año bajo condiciones estériles, lo cual en alguna medida asegura su calidad inicial. Además, en los ensayos no se apreciaron semillas muertas o dañadas.

A partir de la semilla recolectada y germinada se inició una estrategia de cultivo en ambiente controlado, hasta la obtención de plantas adultas que permitieran la reproducción de la especie. Posteriormente, éstas fueron trasplantadas a macetas plásticas, donde las plantas iniciaron sus ramificaciones y desplegaron sus primeros folíolos, alcanzando una altura de 20 a $25 \mathrm{~cm}$ después de 4 semanas de crecimiento. Luego, bajo condiciones de invernadero y transcurridas 8 a 10 semanas, se obtuvo la producción de plantas adultas cuya altura osciló entre 70 y $80 \mathrm{~cm}$, las que iniciaron el proceso de floración y fructificación al cabo de 22 semanas de iniciada la germinación (Fig. 3).
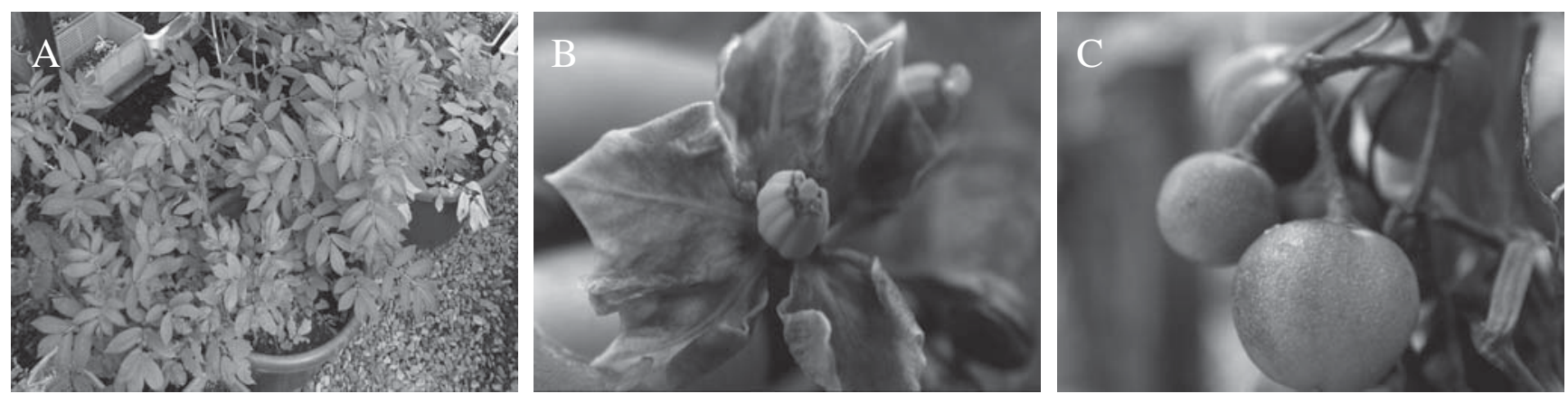

Figura 3. A) Invernadero de policarbonato: producción de plantas adultas en maceteros, B) producción de flores, C) frutos en invernadero (Fotos J. Solano).

Figure 3. A) Polycarbonate greenhouse: production of adult plants en flowerpots, B) production of flowers, C) fruits in greenhouse (Photographs J. Solano).

De este material se obtuvo un promedio de 20 frutos por planta, y la producción de semillas por fruto estuvo dentro del rango de 40 a 70 semillas. Estos valores son similares a los reportados por Jackson \& Hanneman (1996) en estudios de cruzamiento con esta especie. Sobre esta base se puede concluir que a pesar de los bajos porcentajes de germinación obtenidos, la semilla de S. fernandezianum permitió la propagación de la especie. La semilla fue viable después de su almacenamiento y conservación por un año, a temperaturas de $4{ }^{\circ} \mathrm{C}$.

Estos resultados sirven de base para futuras estrategias de conservación que contribuyan en forma importante a reducir el peligro de extinción que afecta a esta especie, respondiendo de esta forma al "Plan de acción mundial para la conservación y utilización sostenible de los recursos fitogenéticos para la alimentación y la agricultura” impulsado por la FAO (1996).

\section{AGRADECIMIENTOS}

Al Proyecto DGIP-UCT 2004-2-02. Dirección General de Investigación y Postgrado, Universidad Católica de Temuco.

\section{BIBLIOGRAFÍA}

Contreras, A. \& D.M. Spooner. 1999. Revision of Solanum section Etuberosum (subgenus Potatoe). In: M. Nee, D.E. Symon, R.N. Lester \& J.P. Jessop. (eds), Solanaceae IV, pp. 227-245. Royal Botanic Gardens, Kew.

Danton, P., E. Breteau \& M. BrafFay. 1999. Les îles de Robinson. Trésor vivant des mers du Sud. Entre légende et réalité. Yves Rocher, Nathan, France. 144 pp.

FAO. 1996. Conservación y utilización sostenible de los recursos fitogenéticos para la alimentación y la agricultura: Plan 
de acción mundial e informe sobre el estado de los recursos fitogenéticos en el mundo. Organización de las Naciones Unidas para la Agricultura y la Alimentación. Italia. $10 \mathrm{pp}$.

HANNEMAN, R.E. \& J.B. BAMBERG. 1986. Inventory of tuber-bearing Solanum species. Bulletin Agricultural Experiment Station, University of Wisconsin. USA. 533 pp.

Hijmans, R.J. \& D.M. Spooner. 2001. Geographic distribution of wild potato species. American Journal of Botany 88: 2101-2112.

Hijmans, R.J., M. Macobs, J. Bamberg \& D. Spooner. 2003. Frost tolerance in wild potato species: Assessing the predictivity of taxonomic, geographic and ecological factors. Euphytica 130: 47-59.

ISTA. 2006. International rules for seed testing. Published by: The International Seed Testing Association (ISTA). 388 pp.

Jackson, S.A. \& R.E. Hanneman. 1996. Potential gene flow between cultivated potato and its wild tuber-bearing relatives: implications for risk assessment of transgenic potatoes. (http://www.nbiap.vt.edu/brarg/brasym96/ jackson96.htm).

Marticorena, C., T. Stuessy \& C. Baeza. 1998. Catálogo de la flora vascular de la Isla Robinson Crusoe o Juan Fernández, Chile. Gayana Botánica 55(2): 187-211.

Ricci, M. 1989. Programa de conservación y recuperación de plantas amenazadas de Juan Fernández. Informe Final, $1^{\text {a }}$ etapa, Proyecto CONAF - WWF - US 3313, Chile, 63 pp.

Ricci, M. 1990. Programa de conservación y recuperación de plantas amenazadas de Juan Fernández. Informe Final, $2^{\text {a }}$ etapa, Proyecto CONAF - WWF - US 3313, Chile, $53 \mathrm{pp}$.

Ricci, M. 1992. Programa de conservación y recuperación de plantas amenazadas de Juan Fernández. Informe Final, $3^{\text {a }}$ etapa, Proyecto CONAF - WWF - US 3313, Chile, $55 \mathrm{pp}$.

Ricci, M. 1998. Técnicas de propagación y viverización de algunas especies de la flora vascular endémica del Archipiélago de Juan Fernández. Países Bajos - CONAF, Chile. 229 pp.

RiccI, M. 2006. Conservation status and ex situ cultivation efforts of endemic flora of the Juan Fernández Archipelago. Biodiversity and Conservation 15: 3111-3130.

Roger, S., T. Stuessy \& R. Rodríguez. 1983. Chromosome numbers from the flora of the Juan Fernández Islands. American Journal of Botany 70(6): 799-810.

Stuessy, T., C. Marticorena, R. Rodríguez, D. Crawford \& O. SILVA. 1992. Endemism in the vascular flora of the Juan Fernández Islands. Aliso 13: 297-307.

Stuessy, T.F., U. Swenson, D.J. Crawford, G. Anderson \& M. SiLva. 1998. Plant conservation in the Juan Fernandez Archipelago, Chile. Aliso 16: 89-98.

TowiLl, L.E. 1983. Longevity of true seed from tuber-bearing and closely related non- tuber-bearing Solanum species. American Journal Potato Research 60: 75-83.

Valkonen, J.P., G. Brigneti, F. Salazar, E. Pehue \& R.W. Gibson. 1992. Interaction of the Solanum spp. of the Etuberosa group and nine potato-infecting viruses and viroid. Annual Applied Biology 120: 301-313.

Recibido: 01.07.10

Aceptado: 01.09.10 